\title{
REDUCTIVE LEACHING OF LOW GRADE MANGANESE ORE (LGMO) USING GLUCOSE IN SULPHURIC ACID: OPTIMIZATION CONDITION USING RESPONSE SURFACE METHODOLOGY
}

\author{
Nurhidayah Muthalib, Norazharuddin Abdullah, and Suhaina Ismail* \\ Strategic Mineral Niche Area, School of Mineral Resources Engineering, Engineering Campus, \\ Universiti Sains Malaysia, Penang, Malaysia, e-mail:*suhaina@usm.my
}

Received Date: August 25, 2016; Revised Date: December 18, 2018; Acceptance Date: December 25, 2018

\begin{abstract}
Manganese (Mn) is an important metal in producing a good quality steel, that the total Mn consumption in this industry reaches 85 to $90 \%$. Despite of this huge demand, Mn faces a shortage supply due to depletion of high grade $\mathrm{Mn}$ ore. As an alternative, low grade manganese ore (LGMO) can be utilized to fulfill the industry demand. The aim of this work is to determine the optimum condition of the reductive leaching process of LGMO using Response Surface Methodology (RSM). The design of experiment (DOE) was made using RSM by Central Composite Design (CCD) with 22 and 3 central points. In this work, the effect of variables such as sulphuric acid concentration (X1) and weight of glucose (X2) were examined. The experimental data obtained from Analysis of Variance (ANOVA) were analyzed. Subsequently, the most significant variable was identified and fitted into a quadratic model. It is found that the interaction between sulphuric acid concentration and amount of glucose (X1X2) is the most important factor in manganese (Mn) extraction. The optimum leaching condition is obtained at $2.5 \mathrm{M}$ sulphuric acid concentration and $2 \mathrm{~g}$ weight of glucose at 60 minutes leaching time. Within this experimental condition, a high level of Mn extraction ratio at $88.97 \%$ is achieved.
\end{abstract}

Keywords: Glucose, Leaching, Low grade manganese ore, Response surface methodology

\section{Introduction}

Positive growth in iron and steelmaking has caught an attention to recover manganese [1]. To produce a good quality steel, manganese (Mn) is added to make the steel more resistance and strength. To date, the Mn consumption in this industry reaches 85 to $90 \%$ of global Mn usage [2]. Despite of its increment demand, Mn faces a shortage supply due to depletion of high grade Mn ore [3]. As an alternative, low grade Mn ore (LGMO) has been utilized to fulfill industries demand [4]. In this case, LGMO can be reduced using varieties of reducing agents such as oxalic acid [5], hydrogen peroxide [6], sodium sulfide [7], carbohydrates [8] and biomass such as cornstalk [9].

In addition, previous researchers have also investigated the leaching of LGMO using glucose. Yet, none of them studied the optimization reductive leaching of LGMO using glucose by Response Surface Methodology (RSM). For example, Trifoni [10] used glucose to reduce Mn. However, the purpose of his work was to study the effects of alcohols on Mn extraction using glucose. Meanwhile, Veglio and Nagib [11-12] did not focus on optimization by RSM. They aimed on the influence of glucose on Mn leaching using factorial design. In 2004, 
Pagnanelli studied leaching of LGMO using nitric acid and glucose [13]. studied the optimization of Mn extraction using glucose, but the Mn source was collected from sea nodules.

In contrast, this work was performed using sulphuric acid as lixiviant which is a stronger acid compared to nitric. Other than that, Biswas [14]

Consequently, there still remains a need for an efficient method that can achieve an optimum extraction of local manganese ore using statistical design method, response surface methodology (RSM). Thus, this work comes out with the objective to determine the optimum condition to leach local manganese ore in sulphuric acid using glucose through statistical design method, Response Surface Methodology (RSM).

\section{Materials and Methods}

\section{Materials}

Manganese ore was collected from Pahang, Malaysia. The elemental analysis detected that the ore is a LGMO which contains not more than $40 \% \mathrm{Mn}$ [2]. Table 1 indicates the elemental analysis result of LGMO.

\section{Table 1: Elemental Composition of LGMO Sample}

\begin{tabular}{cc}
\hline Element & Mass (\%) \\
\hline $\mathrm{Al}$ & 2.79 \\
$\mathrm{Si}$ & 2.88 \\
$\mathrm{Mn}$ & 14.81 \\
$\mathrm{Fe}$ & 3.97 \\
\hline
\end{tabular}

In addition, a XRD analysis conducted using a Siemens D5000 X-ray diffractometer revealed that ore consists of pyrolusite, (Mn (IV) oxide), goethite and quartz [15]. The reference pattern of the XRD was 980062906 for pyrolusite, 980034797 for goethite and 980107202 for quartz. This revealed the ore is LGMO with Mn4+ ion. Figure 1 shows the LGMO XRD pattern.

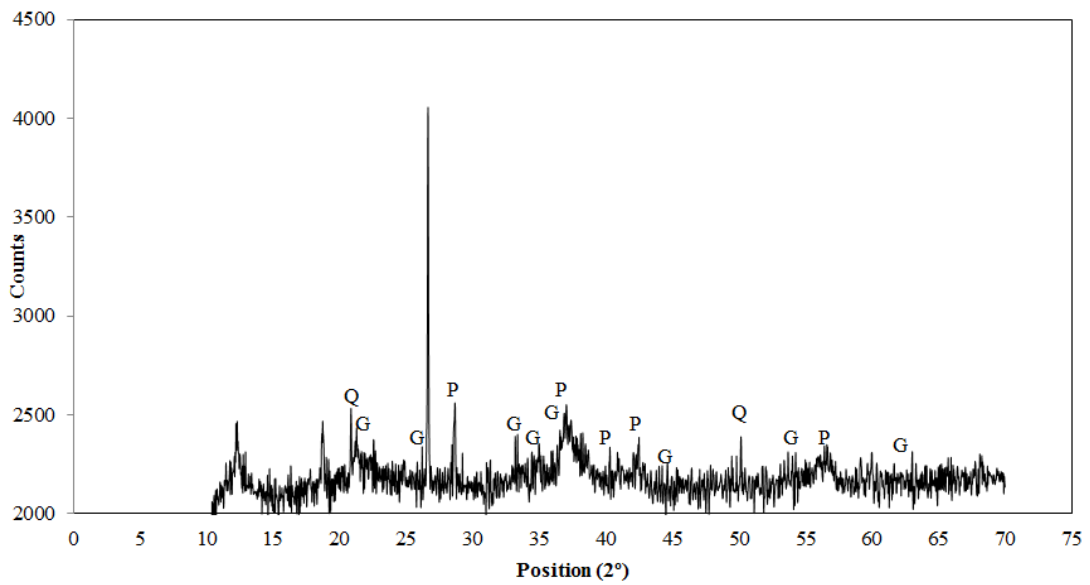

Figure 1: XRD pattern of LGMO (P: pyrolusite, G: goethite and Q: quartz) 
The other raw material was glucose (D- glyceraldehydes, aldose) supplied from Merck 104074. Additionally, chemicals such as sulphuric and nitric acid were also supplied by Merck. Meanwhile, preparation of stock solution and dilution for Inductive Couple Plasma (ICP) were made using ultra pure water obtained from the Elga Ultra Pure System (Purelab Fiex 3, UK).

\section{Reductive Leaching Procedure}

The effect of variables, such as sulphuric acid concentration (X1) and weight of glucose (X2) were studied using Response Surface Methodology (RSM) based on a Central Composite Design (CCD). Factors used were 22 with 3 central points and $\alpha$ value was 1.414. Central points are normally used to reduce error within experiment. Table 2 shows the experimental conditions of this work.

Table 2: Control Factors and Their Levels in Reductive Leaching

\begin{tabular}{lccccc}
\hline Factor & \multicolumn{3}{c}{ Level } \\
\cline { 2 - 6 } & Low (-1) & Medium (0) & High (+1) & \multicolumn{2}{c}{ Star Point, $\boldsymbol{\alpha}$} \\
& & & & $-\alpha$ & $+\alpha$ \\
$\mathrm{X}_{1}, \mathrm{M}$ & 0.5 & 2.5 & 4.0 & 1.0 & 5.0 \\
$\mathrm{X}_{2}, \mathrm{~g}$ & 0.8 & 2.0 & 3.2 & 0.3 & 3.7 \\
\hline
\end{tabular}

* $\mathrm{X}_{1}$ is sulphuric acid concentration, $\mathrm{X}_{2}$ is mass of glucose

The sequence of reductive leaching was carried out according to Design of Experiment (DOE) set by Minitab (Response surface methodology by central composite design). Table 3 displays the sequence of reductive leaching.

Table 3: DOE of Reductive Leaching Using RSM

\begin{tabular}{cccc}
\hline Std Order & Run Order & $\mathbf{X}_{\mathbf{1}}(\mathbf{M})$ & $\mathbf{X}_{\mathbf{2}} \mathbf{( g )}$ \\
\hline 7 & 1 & 2.5 & 0.3 \\
6 & 2 & 5.0 & 2.0 \\
5 & 3 & 0.5 & 2.0 \\
2 & 4 & 4.0 & 0.8 \\
4 & 5 & 4.0 & 3.2 \\
11 & 6 & 2.5 & 2.0 \\
10 & 7 & 2.5 & 2.0 \\
3 & 8 & 1.0 & 3.2 \\
9 & 9 & 2.5 & 2.0 \\
8 & 10 & 2.5 & 3.7 \\
1 & 11 & 1.0 & 0.8 \\
\hline
\end{tabular}

Leaching process set up was slightly modified from Suhaina et al. [4]. Leaching experiment was conducted in $250 \mathrm{~mL}$ three neck flask on stirring hot plate. $100 \mathrm{~mL}$ of sulphuric acid solution was charged into the flask and the solution was stirred by magnetic stirrer. At 90 oC, $10 \mathrm{~g}$ of LGMO was added to perform a batch leaching process. Glucose at desired weight was added into the solution. $5 \mathrm{~mL}$ of leach liquor sample was taken every $30 \mathrm{~min} ., 60 \mathrm{~min}$., 240 min and $480 \mathrm{~min}$. The leach liquor was then filtered using syringe filter of Whatman, Kent, UK, 0.45 um (GMF- PTFE). The liquor was diluted with 10\% HNO3 solution to avoid any kind of 
precipitation due to dilution. The identification of Mn recovery from the leached liquor solution was identified by ICP - MS (Perkin Elmer 7300 DV).

\section{Reagents and Standards Preparation for ICP Testing}

ICP- MS calibration was prepared by $1000 \mathrm{mg} / \mathrm{L}$ stock solutions (Merck, Darmstadt, Germany). Reagents used were $\mathrm{HNO}_{3}$ and high purity water of $18.2 \mathrm{M} \Omega$ obtained from Elga Ultrapure system, (Purelab Fiex 3, UK).

\section{Sample Preparations for ICP Testing}

Determination of total recovery analytes in leach liquor was determined by ICP. Leached liquor was filters through 0.45um glass microfiber (GMF/PTFE) syringe filter (Whatman, Kent, UK). The filtrate was acidified with HNO3 with micropipettes (Gilson, France) with disposable tips and diluted as needed. Triplicate measurements were performed to determine precision. The selected analytical wavelength was $\mathrm{Mn}-257.610 \mathrm{~nm}$.

\section{Results and Discussion}

\section{Manganese Extraction}

Mn extraction generally follows the leaching reaction below.

$$
\mathrm{C}_{6} \mathrm{H}_{12} \mathrm{O}_{6}+12 \mathrm{MnO}_{2}+12 \mathrm{H}_{2} \mathrm{SO}_{4}=12 \mathrm{MnSO}_{4}+6 \mathrm{CO}_{2}+12 \mathrm{H}_{2} \mathrm{O}
$$

In this work, tetravalent $\mathrm{Mn}$ reacts with glucose in sulphuric acid media to produce a maximum recovery of 6,344 ppm Mn2+. Figure 3 shows the overall extraction of Mn according to DOE sequences. Mn extraction rose during the first 30 minutes. Slight increase was observed at 30 minutes to 60 minutes. Beyond that, Mn extraction remained unchanged.

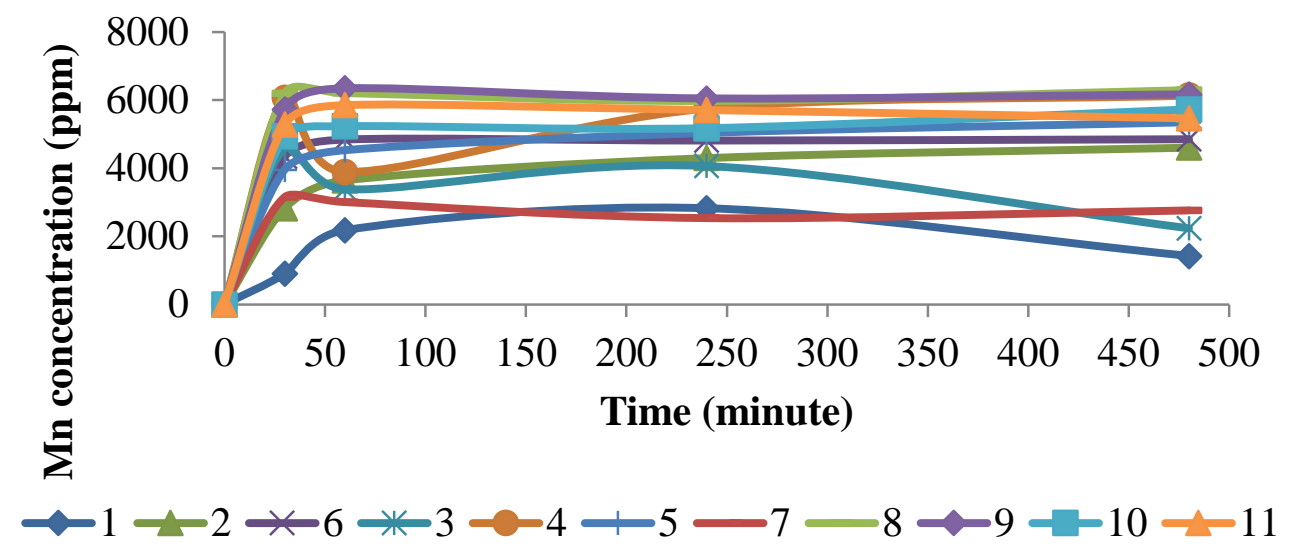

Figure 3: Leach Mn extraction concentrations (ppm)

Roughly, reduction of Mn was rapid when high sulphuric acid concentration used together with the high weight of glucose. The highest extraction of Mn was $88.97 \%$ when it was leached using $2.5 \mathrm{M}$ of sulphuric acid and $2 \mathrm{~g}$ weight of glucose at 60 minutes. The running 
order for this optimum was at 6th run. Table 4 implies the extraction of $\mathrm{Mn}$ for each run experiments at 30 minutes until 480 minutes.

Table 4: Extraction of Mn during Each Run of Experiment

\begin{tabular}{|c|c|c|c|c|c|c|}
\hline \multirow{2}{*}{$\begin{array}{c}\text { Run } \\
\text { Order }\end{array}$} & \multirow{2}{*}{$\begin{array}{c}\mathbf{X}_{1}, \\
\mathbf{M}\end{array}$} & \multirow{2}{*}{$\begin{array}{c}X_{2}, \\
\text { g }\end{array}$} & \multicolumn{4}{|c|}{ Mn Extraction (\%) } \\
\hline & & & $30 \mathrm{~min}$ & $60 \mathrm{~min}$ & $240 \mathrm{~min}$ & $480 \mathrm{~min}$ \\
\hline 1 & 2.5 & 0.30 & 42.66 & 40.68 & 34.30 & 37.36 \\
\hline 2 & 4.5 & 2.00 & 73.30 & 81.84 & 81.35 & 82.00 \\
\hline 3 & 0.5 & 2.00 & 53.40 & 61.15 & 68.01 & 72.22 \\
\hline 4 & 4.0 & 0.80 & 47.72 & 61.53 & 72.60 & 77.79 \\
\hline 5 & 4.0 & 3.20 & 81.89 & 52.60 & 77.73 & 82.86 \\
\hline 6 & 2.5 & 2.00 & 71.30 & 88.97 & 86.78 & 83.07 \\
\hline 7 & 2.5 & 2.00 & 66.66 & 70.65 & 69.90 & 77.35 \\
\hline 8 & 1.0 & 3.20 & 77.79 & 57.15 & 68.66 & 37.75 \\
\hline 9 & 2.5 & 2.00 & 77.25 & 85.67 & 81.67 & 83.30 \\
\hline 10 & 2.5 & 3.70 & 83.67 & 83.89 & 80.76 & 85.08 \\
\hline 11 & 1.0 & 0.80 & 15.16 & 36.80 & 47.68 & 24.04 \\
\hline
\end{tabular}

The identifications of significant factor and interaction effect were made using Analysis of Variance (ANOVA). The quadratic model relationship was significant at $\alpha=0.05$. In addition for lack of fit, $\mathrm{P}>0.05$ point out the model is in good fit. Table 5 tabulated the ANOVA for this work.

Table 5: Mn Extraction ANOVA at (30, 60, 240 and 480) Min.

\begin{tabular}{lllll}
\hline \multicolumn{1}{c}{ Source } & \multicolumn{4}{c}{ Hypothesis, $\mathbf{P}$} \\
\cline { 2 - 5 } & $30 \mathrm{~min}$ & $60 \mathrm{~min}$ & $240 \mathrm{~min}$ & $480 \mathrm{~min}$ \\
\hline Regression & 0.01 & 0.17 & 0.04 & 0.20 \\
Linear & 0.032 & 0.076 & 0.035 & 0.23 \\
$\mathrm{X}_{1}$ & 0.038 & 0.092 & 0.21 & 0.28 \\
$\mathrm{X}_{2}$ & 0.015 & 0.035 & 0.013 & 0.10 \\
Square $_{\mathrm{X}_{1} * \mathrm{X}_{1}}$ & 0.203 & 0.14 & 0.078 & 0.29 \\
$\mathrm{X}_{2} * \mathrm{X}_{2}$ & 0.153 & 0.19 & 0.57 & 0.50 \\
Interaction & 0.148 & 0.068 & 0.031 & 0.13 \\
$\mathrm{X}_{1} * \mathrm{X}_{2}$ & 0.159 & 0.34 & 0.40 & 0.82 \\
Lack of fit & 0.159 & 0.34 & 0.40 & 0.82 \\
\hline
\end{tabular}


The extraction equations and models of Mn recovery are discussed at 30, 60, 240 and 480 minutes. At 30 minutes, the highest extraction was achieved at $80 \%$. This happened when high concentrations of H2SO4 and high weight of glucose were used. For example, at run (5), about 4M H2SO4 was used together with high amount of glucose and at run (10) the concentration reagent of H2SO4 was quite high (2.5M) and maximum weight of glucose was utilized. Hence, only 30 minutes leaching rate was required due to extensive concentration of $\mathrm{H} 2 \mathrm{SO} 4$ enhanced the leaching rate. Increasing $\mathrm{H}$ ion concentration in leaching reaction easily generates soluble Mn2+ [16]. In addition, Mn tetravalent is stable in acid and alkaline oxidizing conditions. The reduction of Mn tetravalent required a reducing agent [17-19]. Therefore, high amount of glucose as reducing agent enhances the reduction of Mn tetravalent to divalent state [14].

From the ANOVA results, a regression equation model can be expressed in order to predict Mn extraction at 30 minutes, as shown in Equation 1.

$$
\mathrm{Y}_{\mathrm{Mn}}(\%)=0.19+0.04 \mathrm{M} \text { (sulphuric acid) + } 0.02 \text { g (glucose) + 0.15 M (sulphuric acid * }
$$

sulphuric acid) +0.15 g (glucose *glucose) +0.16 (sulphuric acid * glucose)

Based on Equation 1, factors of sulphuric acid concentration and weight of glucose both point out positive values. Therefore, increasing these factors will raise Mn extraction. Generally, equation value will indicate the most significant factor to extract Mn ore. For example, interactions between sulphuric acid and glucose have higher values in the equation (0.16). This indicates that this interaction is the most significant factor to extract Mn ore. Therefore, Mn extraction is influenced by the interaction of acid concentration and amount of glucose. High concentration of sulphuric acid reacts with high weight of glucose will produce high Mn extraction. Figure 4 displays the Mn extraction model at 30 minutes.

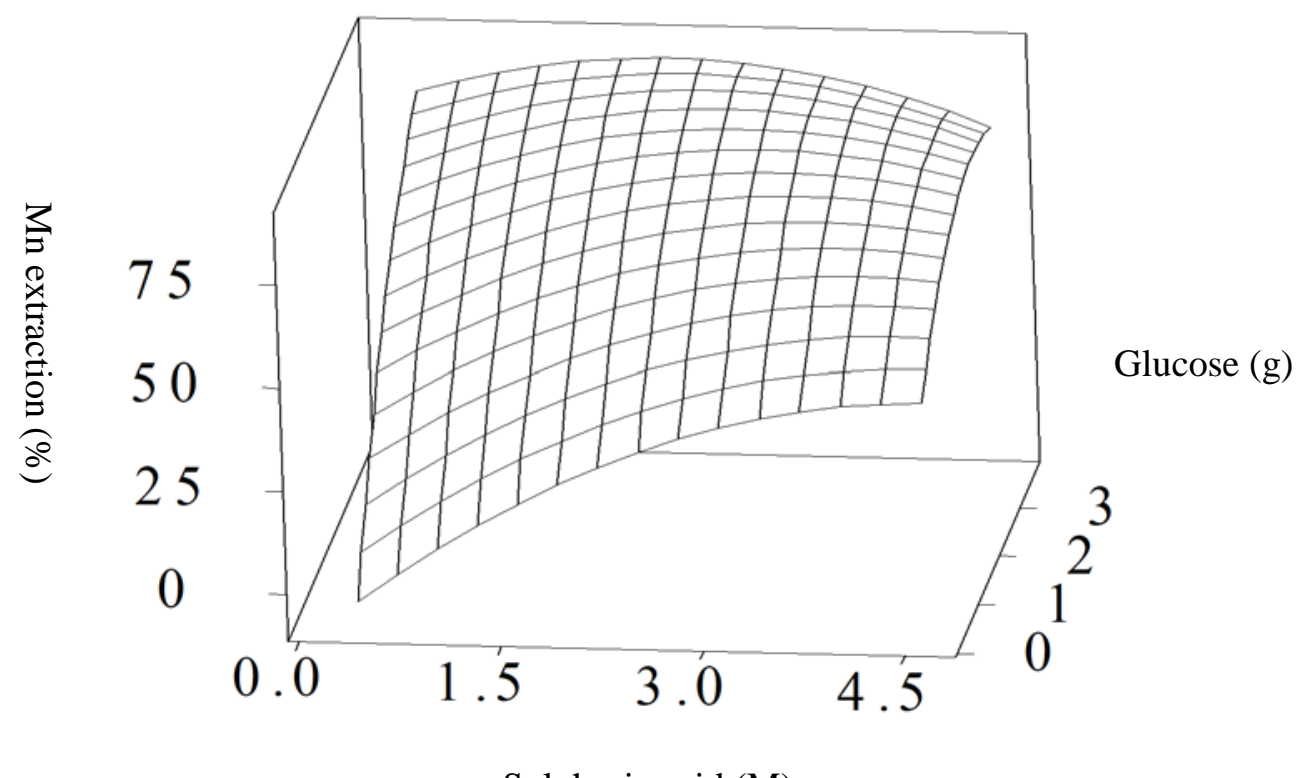

Sulphuric acid (M)

Figure 4: Surface plot of Mn extraction at $30 \mathrm{~min}$ 
At 60 minutes, Mn extraction of up to $80 \%$ was achieved using 2.5M H2SO4 and 2g weight of glucose. The trend can be seen on run 6th, 9th and 10th. The extraction was constant up until 240 minutes. At run 2, recovery also achieved $80 \%$ when using $4.5 \mathrm{M} \mathrm{H} 2 \mathrm{SO} 4$ and $2 \mathrm{~g}$ weight of glucose. As a recommendation, only $2.5 \mathrm{M} \mathrm{H} 2 \mathrm{SO} 4$ and $2 \mathrm{~g}$ weight of glucose are needed to extract $\mathrm{Mn}$ ore in 60 minutes. Equation 2 indicates extraction equation of $\mathrm{Mn}$ at 60 minutes and Equation 3 displays Mn extraction at 240 minutes.

YMn (\%) $=0.4+0.09 \mathrm{M}$ (sulphuric acid) + 0.09 g (glucose) + 0.04 M (sulphuric acid * sulphuric acid) + 0.19 g (glucose *glucose) +0.34 (sulphuric acid * glucose)

YMn (\%) $=0.92+0.21 \mathrm{M}$ (sulphuric acid) $+0.01 \mathrm{~g}$ (glucose) + 0.57 M (sulphuric acid * sulphuric acid) +0.03 g (glucose *glucose) +0.4 (sulphuric acid * glucose)

Coherently, Equation 2 and 3 express increasing sulphuric acid concentration and weight of glucose will raise LGMO reduction. The equation also indicates that the most important factor to reduce LGMO at 60 and 240 minutes was the interaction between sulphuric acid and glucose. Although the interaction between sulphuric acid was highest in 240 minutes, the interaction of sulphuric acid and glucose was actually quite high in Equation 3. Therefore, it can be stated the interaction of sulphuric acid and glucose was a significant factor to produce better Mn extraction. Figure 5 and 6 present the surface plots of Mn extraction at 60 and 240 minutes.

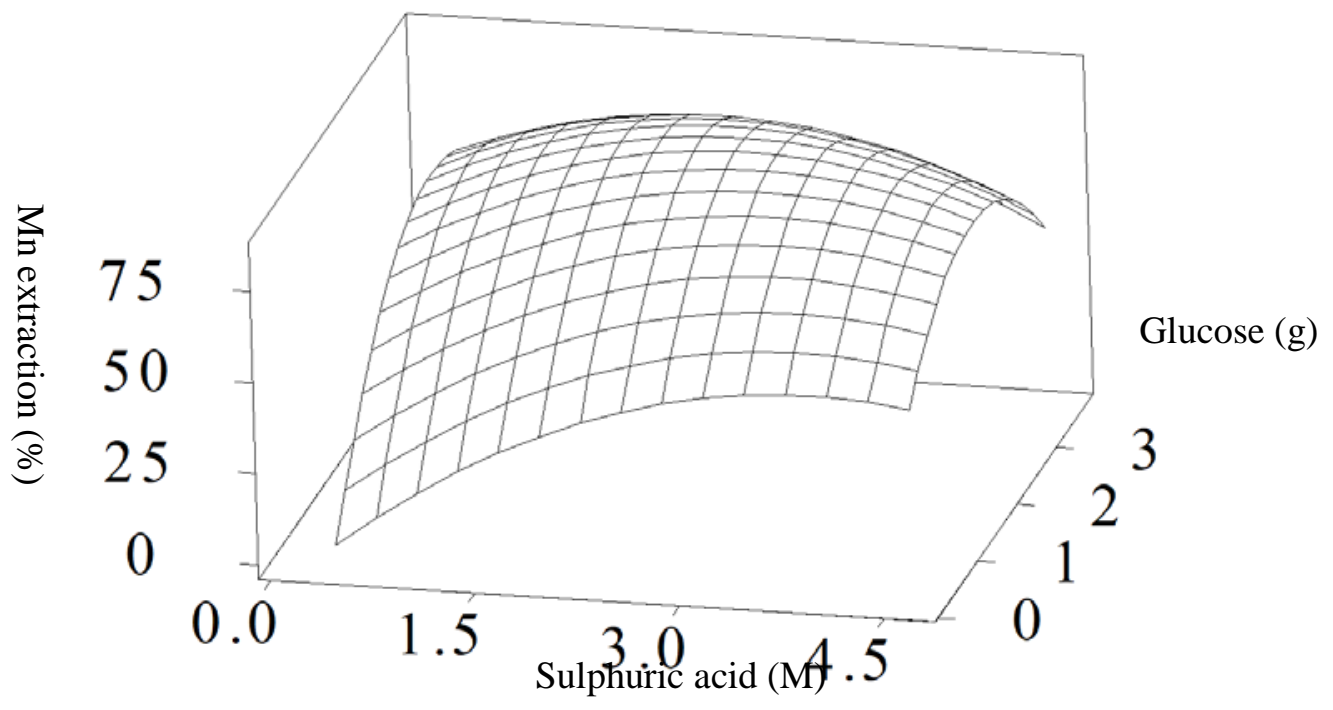

Figure 5: Surface plot of Mn extraction at 60 minutes

Overall, almost all run using more than 2.5M H2SO4 together with $2 \mathrm{~g}$ weight of glucose achieved $75 \%$ Mn extraction leached up until 480 minutes. However, reaction with low sulphuric acid reacted with low weight of glucose to produce insignificant Mn extraction. For example, at 1st run 2.5M H2SO4 reacted with low glucose to generate only $37.36 \%$ extraction up until 480 minutes. Equation 4 specifies the Mn extraction at 480 minutes. 


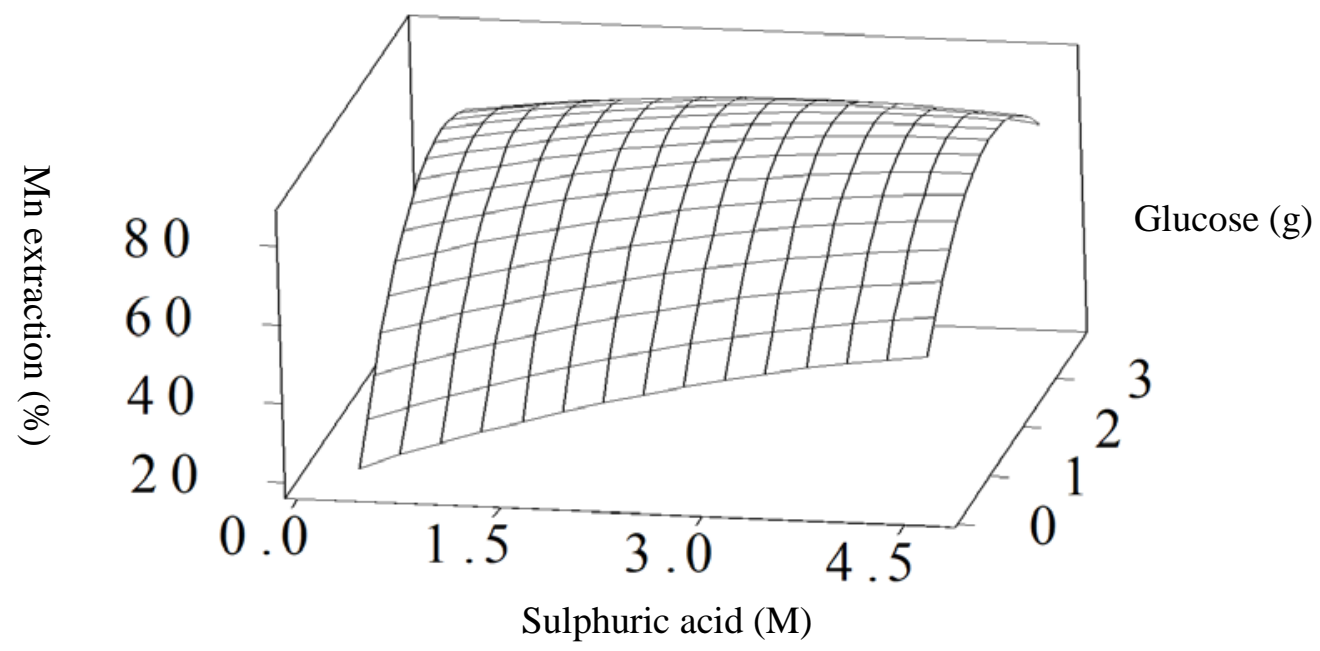

Figure 6: Surface plot of Mn extraction at 240 minutes

YMn (\%) $=0.65+0.28 \mathrm{M}$ (sulphuric acid) $+0.1 \mathrm{~g}$ (glucose) $+0.5 \mathrm{M}$ (sulphuric acid * sulphuric acid) $+0.13 \mathrm{~g}$ (glucose *glucose) +0.82 (sulphuric acid * glucose)

Accordingly, the interaction between sulphuric acid and glucose was most significant in Equation 4. Therefore, the most influencing factor to extract Mn ore was the interaction between sulphuric acid and glucose. Figure 7 demonstrates the model of LGMO extraction at 480 minutes.

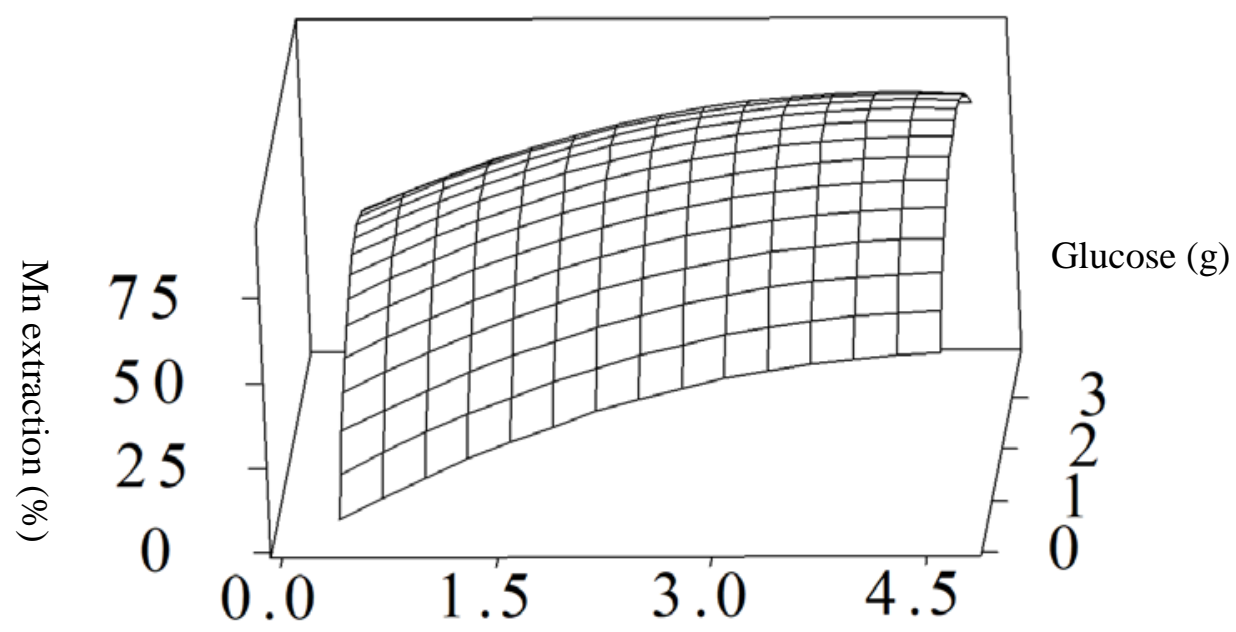

Sulphuric acid (M)

Figure 7: Surface plot of Mn extraction at 480 minutes

The accuracy of above models was measured using the standard deviations. Table 6 expresses the R2 for these models. The accuracy of these models was quite accurate with all models had R2 more than $65 \%$. 
Table 6: Mn Extraction Standard Deviation

\begin{tabular}{cc}
\hline Leaching time & $\mathbf{R}^{\mathbf{2}} \mathbf{( \% )}$ \\
\hline $30 \mathrm{~min}$ & 91.64 \\
$60 \mathrm{~min}$ & 71.16 \\
$240 \mathrm{~min}$ & 85.04 \\
$480 \mathrm{~min}$ & 69.14 \\
\hline
\end{tabular}

\section{Conclusions}

The reductive leaching of local LGMO was successfully performed using glucose as a reductant in sulphuric acid. The optimum extraction of manganese was achieved when leaching was done with high concentration of sulphuric acid and high amount of glucose loading. The best LGMO reduction was $88.97 \%$ obtained at $2.5 \mathrm{M}$ sulphuric acid concentration and $2 \mathrm{~g}$ weight of glucose during 60 minutes leaching time. Based on ANOVA, the most significant factor was interaction between sulphuric acid and weight of glucose to extract LGMO.

\section{Acknowledgement}

The authors gratefully acknowledge the support provided by the Ministry of Education (Higher Education) through Fundamental Research Grant (203/PBAHAN/6071359). Special thanks to Selinsing Gold Mine for giving the sample for use in academic research. The technical support from Mdm. Haslina, Mr. Khairi, Mr. Azrul, Mr. Kemuridan and Mr. Zaini is also much appreciated.

\section{References}

[1] T.A. Lasheen, M.N. El Hazek, and A.S. Helal, "Kinetics of reductive leaching of manganese oxide ore with molasses in nitric acid solution,” Hydrometallurgy, Vol. 98, No. 3-4, pp. 314-317, 2009.

[2] W. Zhang, and C.Y. Cheng, "Manganese metallurgy review. Part I: Leaching of ores/secondary materials and recovery of electrolytic/chemical manganese dioxide," Hydrometallurgy, Vol. 89, Vol. 3-4, pp. 137-159, 2007.

[3] R.N. Sahoo, P.K. Naik, and S.C. Das, "Leaching of manganese from low-grade manganese ore using oxalic acid as reductant in sulphuric acid solution,” Hydrometallurgy, Vol. 62, No. 3, pp. 157163, 2001.

[4] S. Ismail, H. Hussin, S.F. Hashim, S. Fuad, and N.S. Abdullah, "Leaching and kinetic modeling of Malaysian low grade manganese ore in sulfuric acids,” Advanced Materials Research, Vol. 1133, pp. 629-633, 2016.

[5] A.P. Das, S. Swain, S. Panda, N. Pradhan, and L.B. Sukla, "Reductive acid leaching of low grade manganese ores,” Geomaterials, Vol. 2, No. 4, pp. 70-72, 2012.

[6] M.H. Khan, and A. Kurny, "Kinetics of simultaneous dissolution of zinc and manganese from electrolyte paste of spent zinc-carbon dry cell battery in sulfuric acid solution," Materials Science and Metallurgy Engineering, Vol. 2, No. 1, pp. 1-4, 2014.

[7] S. Yan, and Y.R. Qiu, "Preparation of electronic grade manganese sulfate from leaching solution of ferromanganese slag," Transactions of Nonferrous Metals Society of China (English Edition), Vol. 24, No. 11, pp. 3716-3721, 2014.

[8] F. Wu, H. Zhong, S. Wang, and S. Lai, "Kinetics of reductive leaching of manganese oxide ore using cellulose as reductant," Journal of Central South University, Vol. 21, No. 5, pp. 1763-1770, 2014. 
[9] A. Yi, M. Wu, P. Liu, Y. Feng, and H. Li, "Reductive leaching of low-grade manganese ore with pre-processed cornstalk," International Journal of Minerals, Metallurgy, and Materials, Vol. 22, No. 12, pp. 1245-1251, 2015.

[10] M. Trifoni, L. Toro, and F. Vegliò, "Reductive leaching of manganiferous ores by glucose and $\mathrm{H}_{2} \mathrm{SO}_{4}$ : Effect of alcohols,” Hydrometallurgy, Vol. 59, No. 1, pp. 1-14, 2001.

[11] F. Veglio, M. Trifoni, C. Abbruzzese, and L. Toro, "Column leaching of a manganese dioxide ore: a study by using fractional factorial design,” Hydrometallurgy, Vol. 59, No. 1, pp. 31-44, 2001.

[12] S. Nagib, and R.S. Abdelhameed, "Modeling and optimization of reductive leaching of manganese from low-grade manganese ore in $\mathrm{H}_{2} \mathrm{SO}_{4}$ using glucose as reductant," International Journal of Engineering Research and Applications, Vol. 4, No. 1, pp. 281-286, 2014.

[13] F. Pagnanelli, G. Furlani, P. Valentini, F. Veglio, and L. Toro, "Leaching of low-grade manganese ores by using nitric acid and glucose: Optimization of the operating conditions," Hydrometallurgy, Vol. 75, No. 1-4, pp. 157-167, 2004.

[14] A. Biswas, N. Chakraborti, and P.K. Sen, "Multiobjective optimization of manganese recovery from sea nodules using genetic algorithms," Materials and Manufacturing Processes, Vol. 24, No. 1, pp. 22-30, 2008.

[15] N. Muthalib, N.S. Abdullah, H. Hussin, and S. Ismail, "Mineralogical characteristics and quantification of mineral phases in Malaysian low grade manganese ore,” Materials Science Forum, Vol. 888, pp. 453-457, 2017.

[16] A.A. Nayl, I.M. Ismail, and H.F Aly, "Recovery of pure $\mathrm{MnSO}_{4} \cdot \mathrm{H}_{2} \mathrm{O}$ by reductive leaching of manganese from pyrolusite ore by sulfuric acid and hydrogen peroxide," International Journal of Mineral Processing, Vol.100, No. 3-4, pp.116-123, 2011.

[17] Y.F. Long, X.Y. Lv, Y.J. Lv, Y.N. Li, J. Su, and Y.X. Wen, "Overall reduction kinetics of lowgrade pyrolusite using a mixture of hemicellulose and lignin as reductant," Journal of Chemists and Chemical Engineers, Vol. 64, No. 11-12, pp. 593-602, 2015.

[18] A. Yi, M. Wu, P. Liu, Y. Feng, and H. Li, "Reductive leaching of low-grade manganese ore with pre-processed cornstalk," International Journal of Minerals, Metallurgy, and Materials, Vol. 22, No. 12, pp. 1245-1251, 2015.

[19] A.A. Ismail, E.A. Ali, I.A. Ibrahim, and M.S. Ahmed, "Comparative study on acid leaching of low grade manganese ore using some industrial wastes as reductants," The Canadian Journal of Chemical Engineering, Vol. 82, No. 6, pp. 1296-1300, 2004. 